\title{
Relative density correlations are not reliable criteria
}

1 Babak Hamidi MEng(Hons), MIEAust

PhD candidate, Curtin University and member of ISSMGE Ground Improvement Technical Committee, Perth, Australia

2 Serge Varaksin MEng, CFMS

Chairman of ISSMGE Ground Improvement Technical Committee, Paris, France
3 Hamid Nikraz MEng, PhD, FIEAust, CEng, NPER Professor \& Head of Civil Engineering Department of Curtin University, Bentley, Western Australia, Australia
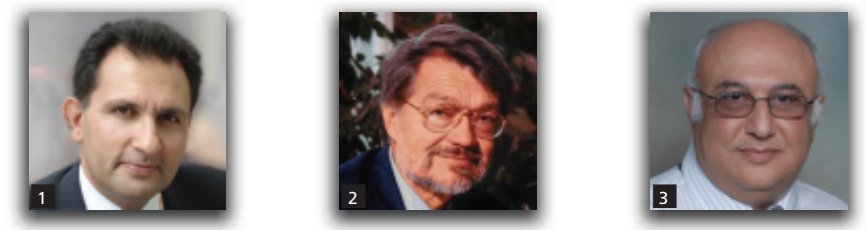

The concept of relative density was developed with the intention of appropriately defining looseness and denseness of sand or sand-gravel soils in a meaningful way; however, there are sufficient amounts of research and case studies to demonstrate the unreliability of this concept due to its large inherent errors. Nevertheless, this parameter found its way early on as a ground improvement acceptance criterion based on the same philosophy that led to its formation. As there was general agreement among engineers that, in any case, direct testing of relative density in actual deep ground improvement projects was difficult, time consuming and costly, direct methods of relative density measurement were abandoned in favour of correlation to other field tests. At first glance, this may have seemed to work out quite well as the conceptual unreliability of relative density did not come into play, but a deeper look could reveal that the proposed correlations are also as unreliable as the concept itself. This paper will discuss the reasons why relative density correlations should not be used as ground improvement acceptance criteria, and alternative reliable criteria will be proposed.

\section{Notation}

a Skempton parameter

$b \quad$ Skempton parameter

$C_{0}, C_{1}$ and $C_{2}$ experimental coefficients

$C_{\text {oc }}$

$C_{\mathrm{u}}$

$D_{\mathrm{d}}$

$D_{50}$

$e_{\max }$

$e_{\min }$

$f_{\text {shell }}$

$K_{0}$

$K_{\mathrm{ONC}}$

$N$

$N_{78}$ overconsolidation coefficient

coefficient of uniformity

relative density (\%)

mean particle size

maximum index void ratio or the reference

void ratio of a soil at the minimum index

density/unit weight

minimum index void ratio or the reference void ratio of a soil at the maximum index density/ unit weight

fines content $(\%)$

shell correlation factor

ratio of effective horizontal to vertical stress for an overconsolidated soil

ratio of effective horizontal to vertical stress for a normally consolidated soil

standard penetration test (SPT) blow count

SPT blow count corresponding to an energy rod ratio of about $78 \%$ from the theoretical free-fall energy

OCR overconsolidation ratio

$q_{\mathrm{c}} \quad$ cone penetration test (CPT) cone resistance $(\mathrm{kPa})$

$q_{\mathrm{cNC}} \quad$ CPT cone resistance for normally consolidated soil $(\mathrm{kPa})$

$q_{\mathrm{coc}} \quad$ CPT cone resistance for overconsolidated soil $(\mathrm{kPa})$

$R \quad$ roundness

$\Delta N_{\mathrm{f}} \quad$ correction term that is a function of fines content

$\sigma^{\prime} \quad$ effective vertical, horizontal or mean stress

depending on the overconsolidation ratio $(\mathrm{kPa})$

$\sigma_{\mathrm{v}}^{\prime} \quad$ effective overburden pressure $(\mathrm{kPa})$

$\phi^{\prime} \quad$ effective internal friction angle

\section{Introduction}

Hamidi et al. (2013) have made a comprehensive review of current ASTM test methods (ASTM, 2006a, 2006b) and studies carried out by numerous researchers to demonstrate the limitations of relative density, and to show that although the objective 
of developing this parameter was to bring the behavioural characteristics of soils together on a common basis in consistent and practically useful relations and to provide a tool for communication between engineers, due to its formulation, relative density is prone to errors with magnitudes of tens of per cent (Hamidi et al., 2013). The amount of inaccuracy associated with relative density is so great that it makes this concept unreliable as a ground improvement acceptance criteria.

As the notion of relative density and the thought of describing the characteristics of soils with one parameter is very attractive indeed, this parameter found its way into ground improvement in the early days of its development. Yet, practical application of relative density in ground improvement projects proved time consuming and costly due to the extraction of high-quality samples of the treated soil. The unreliability of relative density due to its formulation further complicated its usage; hence the correlation of relative density to other commonly used field tests appeared as an attractive means of applying the relative density parameter without the actual usage of the problematic formulation. Thus, it can be occasionally seen that in some projects the specification stipulates that the improved ground must exceed a minimum relative density value or curve based on standard penetration test (SPT) or cone penetration test (CPT) correlations. Correlations, themselves, are as questionable as the concept of relative density, and have been the subject of discussion by experts over many years. In this paper the authors review a number of well-established correlations that are commonly referred to, and will demonstrate the unreliability of relative density correlations as acceptance criteria for ground improvement.

\section{Relationship of relative density with soil characteristics}

A fundamental question that crosses the mind is that, irrespective of the limitations and errors that are associated with relative density concept and formulation (Hamidi et al., 2013), would it be true to say that if two soils had the same relative density, then they would possess the same physical characteristics and will behave the same? It would have been very satisfying if the reply to this question was positive; however, this is not the case, and the use of relative density correlations based on average sand to predict soil behaviour without considering other parameters can result in poor or misleading predictions.

Youd (1973) conducted a study on the maximum and minimum indexes of 13 specimens of different clean sands with less than $5 \%$ fines passing the $0.075 \mathrm{~mm}$ sieve, and was able to identify clear relationships between maximum void ratio, $e_{\max }$, and minimum void ratio, $e_{\min }$, with particle roundness, grain shape, range of particle sizes defined by the coefficient of uniformity, and the type of gradational curve. Figures 1 and 2 show the relationship between limit void ratios with roundness and coefficient of uniformity. Youd did not identify a unique relationship between mean particle diameter $\left(D_{50}\right)$ and limit void ratios; however,

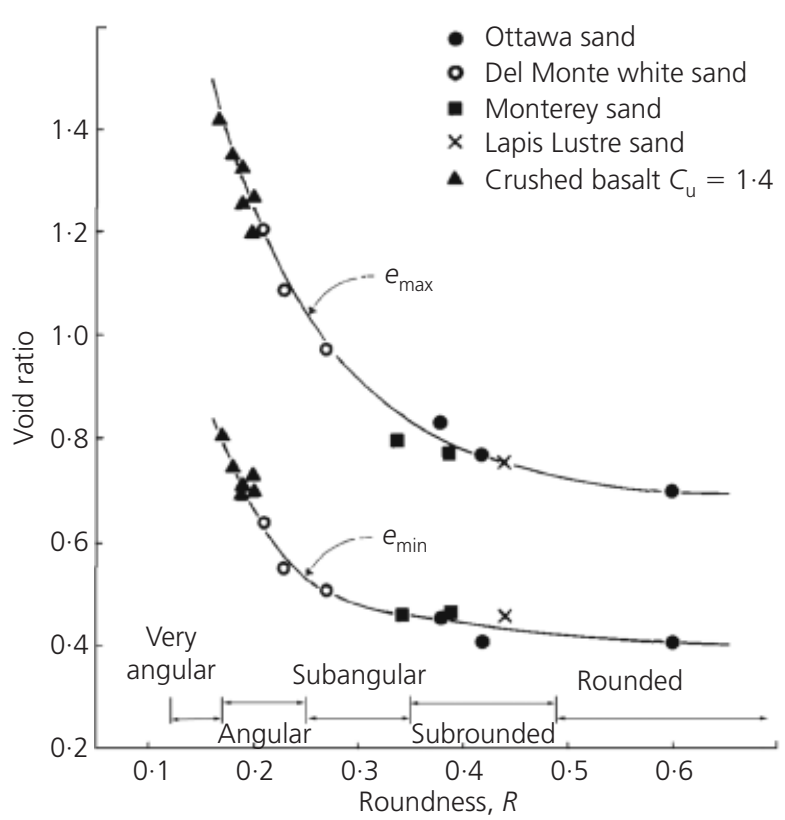

Figure 1. Density limits as a function of grain shape for laboratory fractions with $C_{u}=1.4$ (Youd, 1973)

others such as Tokimatsu and Yoshimi (1983), Skempton (1986), and Cubrinovski and Ishihara (1999) note the importance of the effect of particle diameter on relative density-field test relationships.

Holubec and D'Appolonia (1973) focused their study on the sphericity and the shape of four types of medium to fine sands with the same gradation but varying particle shapes. What they have found is that granular soils at the same relative density can have drastically different engineering properties and have concluded that the use of relative density criteria in design, without considering particle shape, can result in poor or misleading predictions of soil behaviour. As can be seen in Figure 3, Holubec and D'Appolonia show that while both $e_{\min }$ and $e_{\max }$ increase with the increase of the coefficient of angularity, the increase in $e_{\max }$ is considerably more than that for $e_{\min }$ and that the difference between these two limits increases with the angularity of the soil particles.

It can also been seen from the work of Holubec and D'Appolonia that each of the four sands that they tested had separate and distinct relative density versus friction angle relationships whereas although the roundest particles had the least friction angles and exhibited the minimum increase in friction angle with increasing relative density, the sands with angular particles had the highest friction angles with an intermediate increase with increasing relative density. What can be assessed is that friction angle is a function of both relative density and particle shape. In fact, this research suggests that equally large differences in friction angle are possible with variations of particle shape as with changes in relative density. 


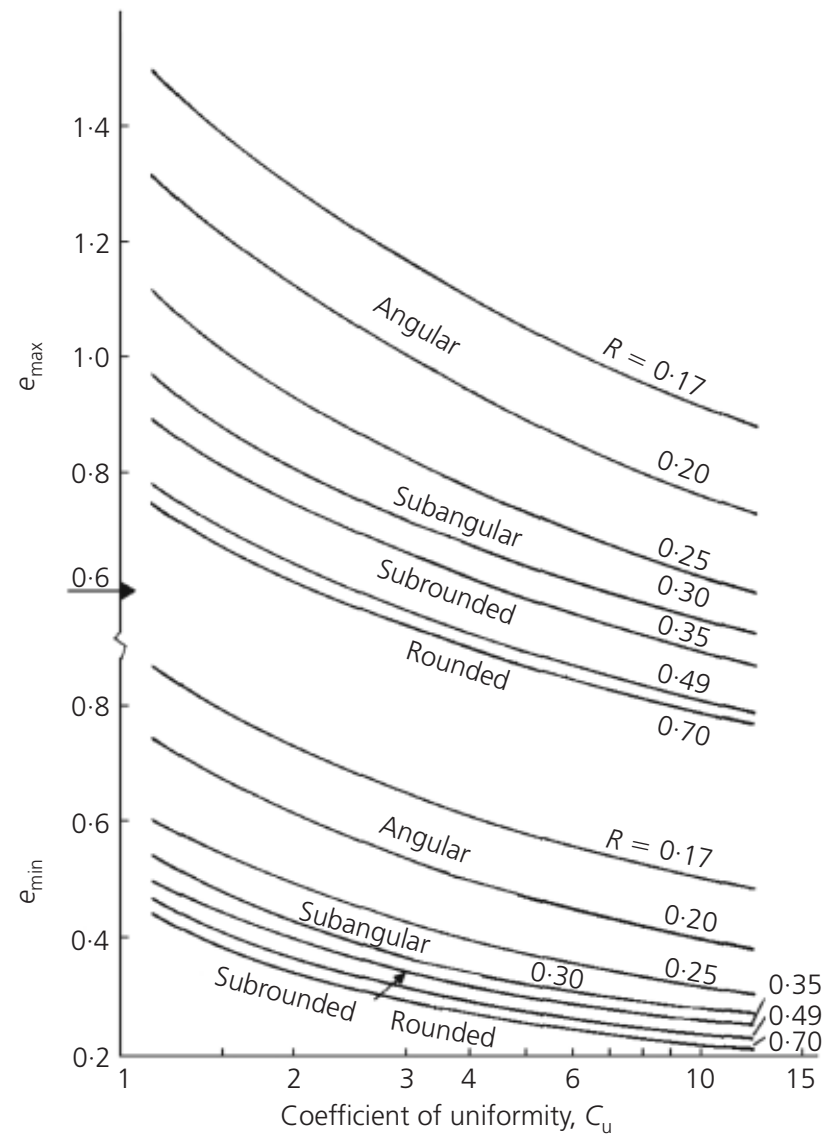

Figure 2. Generalised curve for estimating $e_{\max }$ and $e_{\min }$ from gradational and particle shape characteristics. Curves are only valid for clean sands with normal to moderately skewed grain size distributions. (Youd, 1973)

Stress-strain relations are also influenced by particle shape. Holubec and D'Appolonia show that the more angular the particles are, the greater the failure strain is for a given relative density. Holubec and D'Appolonia perform a miniature penetration test using a $12.5 \mathrm{~mm}$ diameter rod that was driven to a depth of $20 \mathrm{~cm}$ in sands that were compacted to selected densities. The data showed a marked increase in the penetration resistance with the increase of angularity of the sand particles. For example they observed that the required number of blows for a sand with angular particles is nearly double the values for a subrounded sand when relative density is $70 \%$. Conversely, a blow count of 20 indicated a spread in relative densities from 66 to $86 \%$.

More recently, Liu and Lehane (2012) have studied the behaviour of four uniformly graded silica soils with similar mineralogical compositions but with distinctly different particle shapes. The soils were subjected to centrifuge CPT and direct shear tests at different relative densities in dry and saturated states. In these tests, gradation and material were controlled to be similar; hence any differences in test results could be attributed to the grain's sphericity, roundness and roughness.

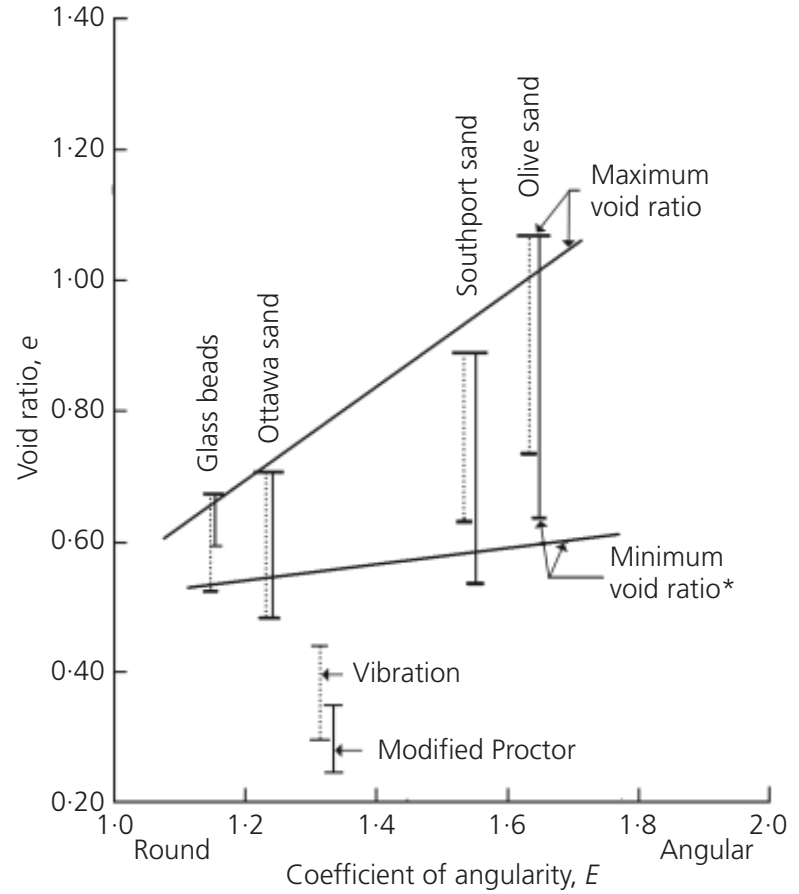

Figure 3. Effect of particle shape on minimum and maximum void ratios (Holubec and D'Appolonia, 1973). *Minimum void ratio based on modified Proctor compaction test, except for glass beads

Figure 4 shows the differences between effective peak and critical state friction angles at different effective vertical stresses for the four soils when relative densities were 20,50 and $80 \%$. It can be seen that while the general trend is the reduction of the friction angle differences at higher effective vertical stresses, the lines

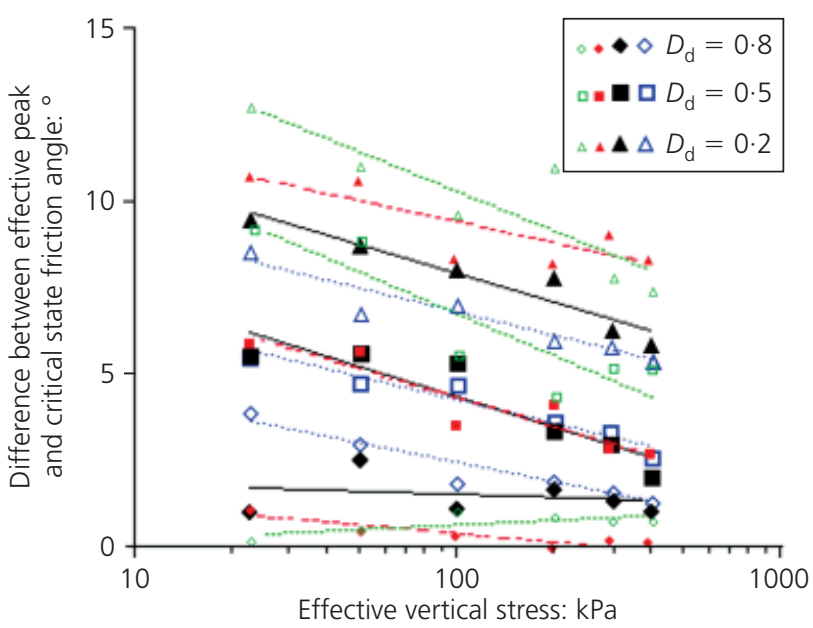

Figure 4. Difference between effective peak and critical state friction angles in four different uniformly graded silica soils with similar mineralogical compositions at different relative densities; reconstructed from Liu and Lehane (2012) 
fitted to the plotted points of the four soils are distinctly different for any of the three relative density values.

It can be understood from the work of Youd (1973), Holubec and D'Appolonia (1973), and Liu and Lehane (2012) that applying relative density correlations from one type of sand to the other, even if the gradation and mineralogy are similar, could lead to very misleading results.

\section{Correlation of relative density with field tests}

By definition, correlation is a statistical relation between two or more variables such that systematic changes in the value of one variable are accompanied by systematic changes in the other. Correlations are not physical laws or theorems; they are simply statistical relations and only meaningful once their scatters, deviations and variances are known. In general, empirical correlations are derived from a set of specified data under special conditions that are not necessarily applicable to other data, soil and conditions. In addition to the inherent drawbacks and limitations of relative density, when consideration of a correlation's applicable domain is not taken into account, inaccurate and unrepresentative outcomes should be expected.

This paper will limit its review and discussion to some of the better known relative density-field test relationships as discussing all studies is beyond the scope of a journal paper; however, the trend of this discussion and its conclusions is equally applicable to any other such correlation. Furthermore, the limitations and drawbacks that are associated with any of the field testing methods are not considered herein as they are different issues and not directly associated with the unreliability of relative density.

\subsection{Relative density-standard penetration test correlations}

Although the first correlations between relative density and SPT were qualitatively realised by Terzaghi and Peck (1948), probably the best known and most referenced estimation method has been developed by Gibbs and Holtz (1957) based on data obtained from calibration chamber tests performed at the US Bureau of Reclamation. Gibbs and Holtz performed tests on a fine-grained and a coarse-grained sand by placing them at controlled densities and moistures in a heavy steel tank, $0.9 \mathrm{~m}$ in diameter and $1.2 \mathrm{~m}$ in height. Overburden pressure was realised by load plates and loading springs. The maximum density was determined by vibrating the saturated material to constant density or by using extreme compaction hammer blows, whichever gave higher values, in a container of known volume. Minimum density was found by lightly pouring the dry material into a container of known volume.

Gibbs and Holtz carried out this research in 1957 (Gibbs and Holtz, 1957); that is, 12 years before ASTM published its first standard on relative density (ASTM, 1969). Obviously the testing procedure for measuring limit densities could not have been as per a non-existent standard of its time. Today, it is known that due to its formulation, relative density is prone to large errors whereas Yoshimi and Tohno (1973) have shown, as an example, that if minimum index density increases by $1 \%$ then relative density will reduce by $14 \%$. Thus, even small differences in limit indexes originating from Gibbs and Holtz's testing method could have had significant impacts on the calculated relative densities.

Unlike the rather well known Gibbs-Holtz relative density versus overburden pressure diagram that has been referenced in numerous publications, those who have actually seen the Gibbs and Holtz (1957) paper know that they published a relative densitypenetration resistance chart (as reconstructed in Figure 5), not the better known chart of Figure 6 which first appeared in Earth Manual (Bureau of Reclamation, 1960) in accordance with Gibbs and Holtz. It is noted that the Bureau of Reclamation (Bureau of Reclamation, 1998) does not use the term correlation, but rather refers to the chart as the criterion for predicting the relative density of sand. In addition to the limitations that ASTM (2006a, 2006b) has in place for the application of relative density, the Bureau of Reclamation also limits the use of its chart to sands containing less than $10 \%$ fines and no gravels.

Osterberg and Varaksin (1973) extracted frozen soil samples from Lake Michigan and compared them with what was estimated by Gibbs and Holtz. Predictions were quite different from reality and it was concluded that relative densities obtained from SPT using the Gibbs and Holtz chart had no relationship to the actual relative densities. This study was an indication that relative density correlation of one sand cannot be extended to any other sand.

Contrary to the general overconfidence by others, Holtz (1973) does not share the same unconditional and unlimited trust that others have for their chart. In the discussion on the results of Osterberg and Varaksin (1973), Holtz notes that everyone should recognise that the SPT is a relatively crude test and no one should expect to determine the relative density of sands to the nearest $1 \%$ or anything like that, and further adds that he and Gibbs developed a set of correlations to take into account the effect of overburden pressures, and that they never indicated that the sets of curves developed at that time were necessarily applicable to all cohesionless soils under all conditions. More importantly, he clarifies that they had always laid stress on relative density trends indicated by SPT values rather than the specific individual values. This discussion suggests that the research of Gibbs and Holtz may have been blown out of proportion, and rather than acknowledging the trend of relative density versus overburden pressure it is used systematically for something that was never the intention.

Meyerhof (1957) has formulated the coarse sand graph of Gibbs and Holtz (1957) and expressed it in the form of Equation 1 or Equation 2 (after conversion to SI units); however, in practice this equation is often extended to most types of sands regardless of the soil particle size and shape, gradation and mineralogy. 


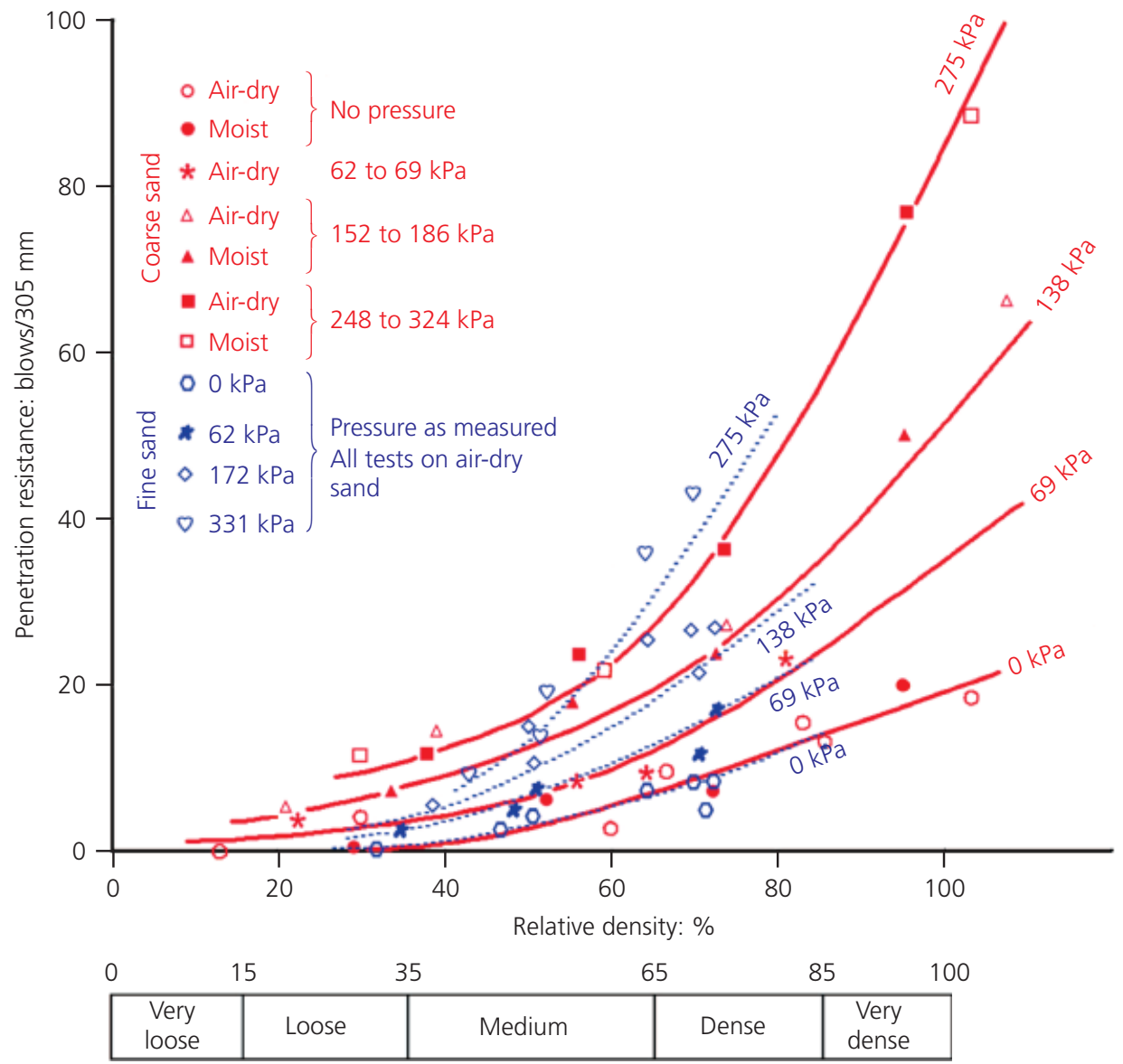

Figure 5. Curves of relative density plotted against penetration resistance for fine and coarse sands, reconstructed from Gibbs and Holtz (1957)

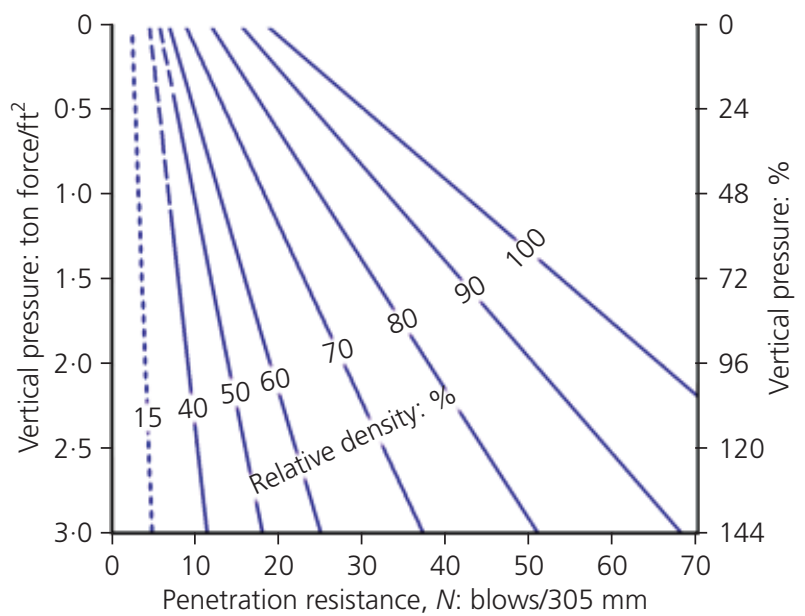

Figure 6. Criterion for predicting relative density of sand from the penetration resistance test (Bureau of Reclamation, 1998) (1 ton $/ \mathrm{ft}^{2}=107 \cdot 3 \mathrm{kN} / \mathrm{m}^{2}$ )
Obviously, this will further cast doubt on the reliability of the correlation as it is very clear in the original Gibbs and Holtz research that the fine and coarse sand curves do not coincide.

1. $N=\left(17+0 \cdot 25 \sigma_{\mathrm{v}}^{\prime}\right) D_{\mathrm{d}}^{2}$ where $N$ is the SPT blow count, $D_{\mathrm{d}}$ is the relative density expressed as a ratio (not percentage), $\sigma_{\mathrm{v}}^{\prime}$ is the effective vertical stress $(\mathrm{kPa})$.

In lieu of Equation 1, Haldar and Tang (1979) have approximated Gibbs and Holtz's relative density correlation using Equation 3 (after conversion to SI units). 
3. $N=20 D_{\mathrm{d}}^{2 \cdot 5}+0 \cdot 21 \sigma_{\mathrm{v}}^{\prime} D_{\mathrm{d}}^{2}$

Haldar and Tang who note the difficulty of obtaining data that actually includes measurements of $D_{\mathrm{d}}, N$ values and $\sigma_{\mathrm{v}}^{\prime}$ have plotted against calculated (using Gibbs and Holtz's relationship) relative density of what they could gather (Gibbs and Holtz, 1957; Marcuson and Bieganousky, 1977; Moretto, 1954; Varaksin, 1970; $\mathrm{Wu}, 1957)$ onto the graph of Figure 7. It can be seen that there is considerable spread about the $45^{\circ}$ bisecting parity line. The majority of data is above the $45^{\circ}$ line, suggesting that Gibbs and Holtz's relationship may be non-conservative. Figure 7 also shows a mean line, an upper bound (line B) and a lower bound (line E). For a given value of relative density calculated from Gibbs and Holtz's relationship, the measured relative density may be assumed to follow a triangular distribution between the upper and lower bounds and be symmetrical about the mean line. On this basis, the mean measured relative density is only $75 \%$ of the calculated value and the scatter around the mean has a coefficient of variation of $27 \%$ which is constant at any relative density calculated. Haldar and Tang conclude that except for sand exhibiting a small difference between the limit indexes, the uncertainty in direct laboratory determination of in-situ relative density (which is prone to large errors) is expected to be less than estimations using Gibbs and Holtz's relationship for normally consolidated deposits, and that a systematic bias appears to exist in Gibbs and Holtz's prediction relationship.

Peck and Bazaraa (1969) proposed Equations 4 (after conversion to SI units) for predicting relative density. Comparison of these relations will show that for equal $N$ values, these equations will consistently yield higher relative density estimates than Gibbs and Holtz's relationship.

4a. $D_{\mathrm{d}}=\sqrt{\frac{N}{20+0 \cdot 84 \sigma_{\mathrm{v}}^{\prime}}}$ for $\sigma_{\mathrm{v}}^{\prime}<72 \mathrm{kPa}$

4b. $\quad D_{\mathrm{d}}=\sqrt{\frac{N}{65+0 \cdot 21 \sigma_{\mathrm{v}}^{\prime}}}$ for $\sigma_{\mathrm{v}}^{\prime} \geqslant 72 \mathrm{kPa}$

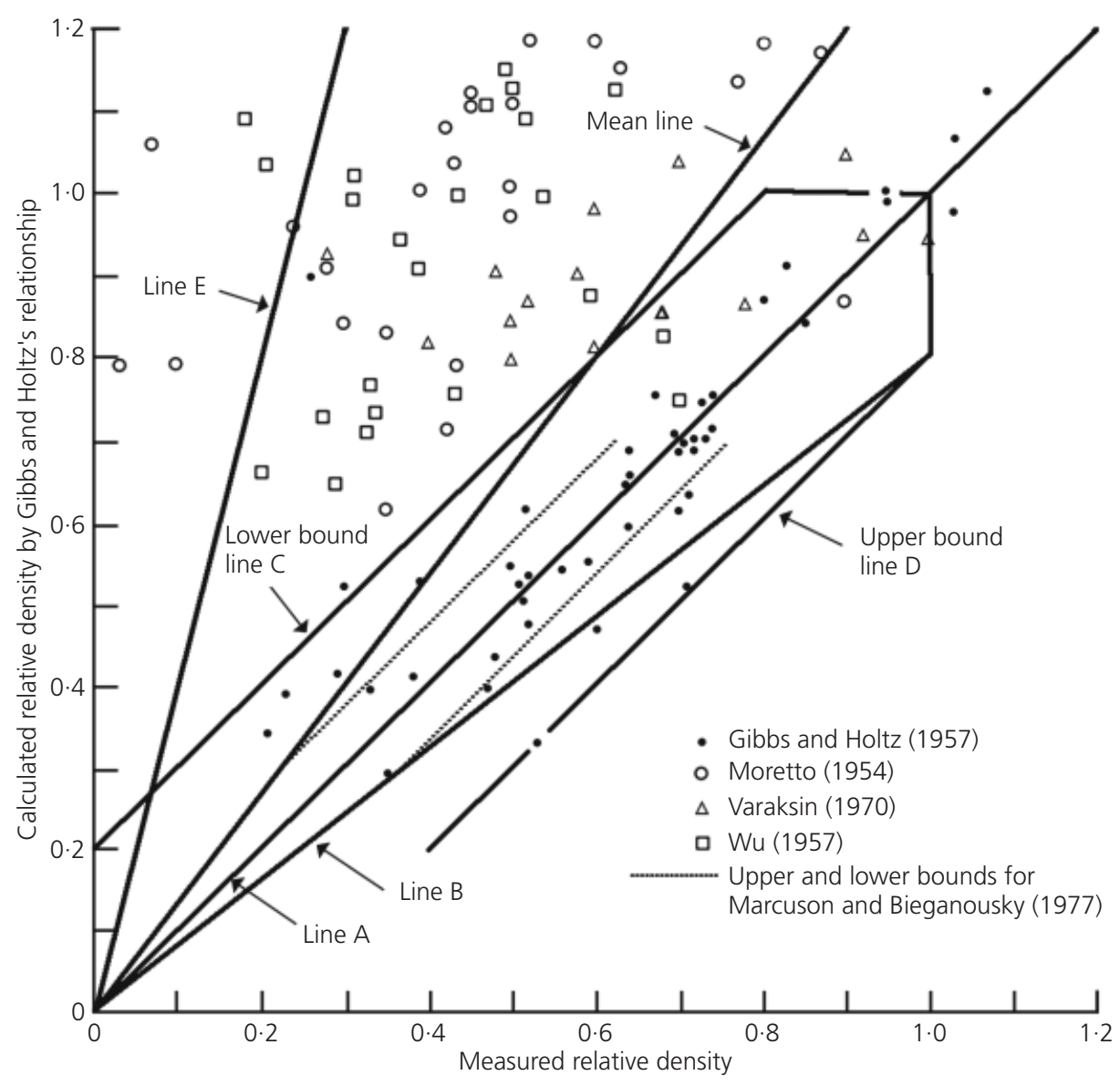

Figure 7. Comparison of measured and calculated relative density using Gibbs and Holtz's relationship (Haldar and Tang, 1979) 
Lacroix and Horns (1973) note that in their experience Gibbs and Holtz's method of predicting relative density yields results that are too high for heavily compacted fill. As noted by Peck and Bazaraa (1969), they also agree that while Gibbs and Holtz greatly underestimate $N$ values corresponding to $100 \%$ relative density, Bazaraa's (Bazaraa, 1967) relationship was in better agreement with the blow count data.

Marcuson (1978), who refers to a study on four sands at various relative densities under overburden pressures in the laboratory of the US Army Waterways Experiment Station (WES), concluded that a simple family of curves relating $N$ values, overburden pressure and relative density for all sands under all conditions is not valid. He also concluded that based on comparisons between the relationships presented by Gibbs and Holtz, Bazaraa and WES, SPT is not sufficiently accurate to be recommended for final evaluation of the density or relative density, unless sitespecific correlations are developed.

Skempton (1986) proposes the relationship between relative density and $N$ values in the general form of Equation 5, with $a$ and $b$ as two parameters. Skempton tested five different types of sand and proposed values for $a$ and $b$ ranging respectively from 15 to 30 and from 17 to 24 in the imperial system (ton/ $/ \mathrm{ft}^{2}$ $\left(1 \mathrm{ton} / \mathrm{ft}^{2}=107 \cdot 3 \mathrm{kN} / \mathrm{m}^{2}\right)$. It can be seen that the values for these parameters can be respectively $100 \%$ and $40 \%$ more than the least values. Inclusion of Bazaraa (1967) would even further increase the figures respectively to $300 \%$ and $47 \%$. This clearly suggests that the specific studies of one site cannot simply be used on other sites.

5. $\quad D_{\mathrm{d}}=\sqrt{\frac{N}{a+b \sigma_{\mathrm{v}}^{\prime}}}$

Among his observations, Skempton (1986) notes that at a given relative density and overburden pressure, $N$ values are higher for sands with larger grain sizes $\left(D_{50}\right)$. He also assesses that there is direct evidence that ageing of sand will increase the SPT blow counts. This suggests that not only is relative density influenced by numerous other parameters such as gradation, particle size, overburden pressure, mineralogy and particle shape, and hence its correlation in one sand may not be reliable for any other sand, but even the correlation for a soil at a specific time or state may be not valid and applicable at other times and conditions. Skempton also identifies a relationship between the effects of overconsolidation and relative density and introduces an overconsolidation coefficient, $C_{\mathrm{oc}}$, into Equation 5 to derive Equation 6.

6. $D_{\mathrm{d}}=\sqrt{\frac{N}{a+C_{\mathrm{oc}} b \sigma_{\mathrm{v}}^{\prime}}}$

The coefficient $C_{\mathrm{oc}}$ itself can be calculated from Equation 7 .
7. $C_{\mathrm{oc}}=\frac{1+2 K_{\mathrm{O}}}{1+2 K_{\mathrm{ONC}}}$

Parameters $K_{\mathrm{ONC}}$ and $K_{\mathrm{O}}$ are the ratio of effective horizontal to vertical stresses, respectively, when the soil is normally consolidated and overconsolidated. Skempton refers to Mayne and Kulhawy (1982) for determining these coefficients as a first approximation according to Equations 8 and 9

\section{8. $K_{\mathrm{ONC}}=1-\sin \phi^{\prime}$}

9. $K_{\mathrm{O}}=K_{\mathrm{ONC}}(O C R)^{\sin \phi^{\prime}}$

where $O C R$ is the overconsolidation ratio and $\phi^{\prime}$ is the effective internal friction angle.

Tokimatsu and Yoshimi (1983), who were studying soil liquefaction, modified Equation 2 to Equation 10 by taking into account the effect of fines content, $F_{\mathrm{c}}$, and introducing $\Delta N_{\mathrm{f}}$ as a correction term (refer to Table 1). However, they themselves did not demonstrate confidence in their proposed equation and note that its application had yet to be proven.

10. $D_{\mathrm{d}}=0.21 \sqrt{\frac{N}{0 \cdot 7+\frac{\sigma_{\mathrm{v}}^{\prime}}{98}}+\frac{\Delta N_{\mathrm{f}}}{1 \cdot 7}}$

More recently, Hatanaka and Feng (2006) have carried out a comparative study on high-quality undisturbed samples recovered by the in situ freezing method. The material used in this study was less than $4.75 \mathrm{~mm}$ in size and $D_{50}$ was less than $1 \mathrm{~mm}$. They then compared the measured and calculated values of relative density using Meyerhof (1957), Bazaraa (1967) and Tokimatsu and Yoshimi (1983). As shown in Figure 8, the estimated values of relative density based on Meyerhof's method were in the range +15 to $-45 \%$ of the measured values. Similar to Haldar and Tang (1979), this research also shows a large scatter of results about the prediction equation; however contrary to Haldar and Tang, here the scatter is mostly concentrated on the lower side of the bisecting parity line, suggesting that Meyerhof's equation is

\begin{tabular}{lc}
\hline Fines content: $\%$ & $\Delta N_{f}$ \\
\hline $0-5$ & 0 \\
$5-10$ & Interpolate \\
$10-$ & $0 \cdot 1 F_{c}+4$
\end{tabular}

Table 1. $\Delta N_{f}$ - fines content correlation (Tokimatsu and Yoshimi, 1983) 


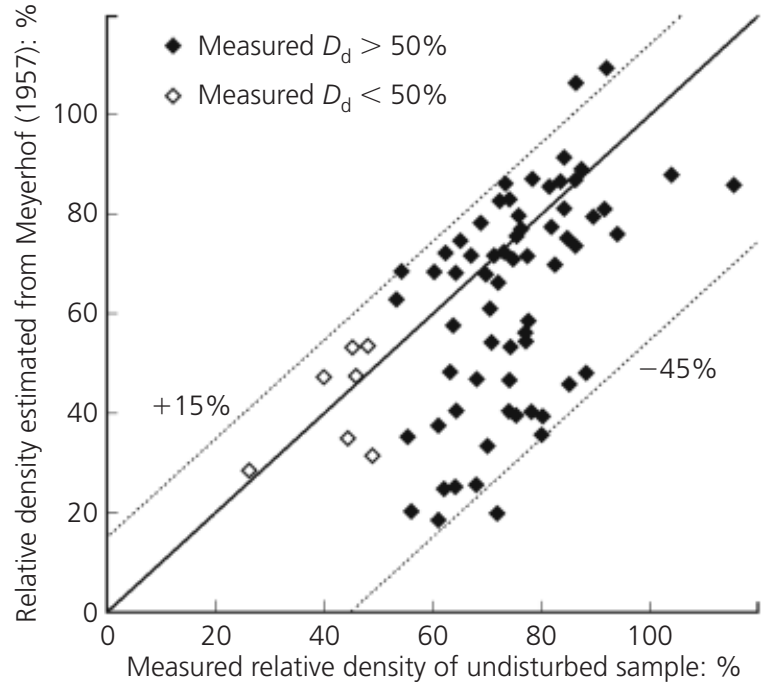

Figure 8. Comparison of measured and calculated relative density using Meyerhof's equation (Hatanaka and Feng, 2006)

generally underestimating relative density. Similar results were also obtained when Tokimatsu and Yoshimi's (Tokimatsu and Yoshimi, 1983) correlation was used. In this case, the range of estimated to measured relative density was from +25 to $-20 \%$.

Tatsuoka et al. (1978), who examined the accuracy of Meyerhof's (Meyerhof, 1957) expression by studying the results of SPT on normally consolidated sandy deposits and conventional undisturbed samples, made a similar assessment and concluded that Meyerhof's formulation tends to underestimate the relative density of fine sands and silty sands.

For estimating relative density, Cubrinovski and Ishihara (1999) note the importance of grain size and propose Equation 11

11. $D_{\mathrm{d}}=\sqrt{\frac{N_{78}\left(e_{\max }-e_{\min }\right)^{1 \cdot 7}}{9} \sqrt{\frac{98}{\sigma_{\mathrm{v}}^{\prime}}}}$

where $N_{78}$ is the SPT blow count corresponding to an energy rod ratio of about $78 \%$ from the theoretical free-fall energy.

Cubrinovski and Ishihara report that by using Equation 11, in $84 \%$ of instances they were able to calculate relative density within a deviation of $20 \%$ from the measured values, and more than half the calculations were within $10 \%$ deviation. Although this amount of accuracy is by no means sufficient to reliably establish an acceptance criterion upon, in any case, here three parameters are involved, two (limit void ratios) of which are included in the original definition of relative density, and the third (the $N$ value) is a function of the in situ density. It may be simply more appropriate to use the definition of relative density (ASTM, 2006a, 2006b) to calculate a value which is prone to error (Hamidi et al., 2013) rather than going to the trouble of estimating a value which may be even more erroneous and misleading.

Many other $S P T-D_{\mathrm{d}}$ correlations could be introduced and reviewed and this discussion continued endlessly; however, what is evident and established is that due to the numerous other parameters that influence the outcome, SPT-relative density correlations will have an unreliably large amount of scatter and cannot be trusted as ground improvement criteria.

\subsection{Relative density-cone penetration test estimations} Many researchers, for example Jamiolkowski et al. (2001), note that the first CPT versus relative density correlation was published by Schmertmann (1976). This is not entirely accurate as the authors are aware of at least one previous publication by Schmertmann (1975) and a reference by Schmertmann (1978) to Mitchell and Gardner (1975).

Although the authors agree that Schmertmann's (Schmertmann, 1976) publication should be recognised as an early research on the subject, it has unfortunately been published in the form of a contract report for WES and today this document is not even available in WES's own library (Report DACW 38-76-M 6646 requested 16/03/2011). The authors have unsuccessfully attempted to obtain a copy of the report through numerous sources, and to date have not met anyone who has actually read the publication. It can only be speculated that many researchers who are more recently referring to this publication have also never read the original publication and are simply citing information from other publications. This can be quite concerning due to possible publication errors, misinterpretations or the fact that each of the intermediate authors only extract that scope of work which is relevant to their own study. By reviewing Schmertmann (1978) and other research such as Villet and Mitchell (1981) the authors understand that the updated correlation of Schmertmann (1976) is the same as that which was later published in Schmertmann (1978).

Schmertmann (1978), who himself was aware that cone resistance is significantly affected by grain size distribution, cementing, lateral stresses, depth of overburden, compressibility, pore pressure and thin layer effects, modified and updated his earlier work (Schmertmann, 1975) after performing 80 more tests in a calibration chamber with a $1.2 \mathrm{~m}$ diameter on two artificial sands with opposite extreme crushabilities, two natural fine sands, and one natural and one artificial medium sand and proposed a correlation chart which only takes into account the effect of vertical effective stress and is for normally consolidated, recent, uncemented fine SP sands. He also proposed a correction factor for converting overconsolidated sands' cone resistances, $q_{\mathrm{cOC}}$, to normally consolidated sands' cone resistances, $q_{\mathrm{cNC}}$. Once simplified, the expression will take the form of Equation 12 
12. $\frac{q_{\mathrm{cOC}}}{q_{\mathrm{cNC}}}=1+\frac{3}{4}\left(4 O C R^{0.42}-1\right)$

As shown in Figure 9, there are significant differences between the relative density estimations of Schmertmann (1975) and Schmertmann (1978). Although Schmertmann (1978) does not show the scatter of testing results, he does note that for clean quartz sands his chart is able to estimate relative density with a standard deviation of about $10 \%$. The standard deviation of Schmertmann (1975) was 7\%. This suggests that irrespective of the scatter which one may experience in one study, there is a strong possibility that the correlation would be almost meaningless for another soil.

This has also been observed by Villet and Mitchell (1981) who performed a series of tests on four gradations of a commercially available windblown dune sand in a calibration chamber with a diameter of $0.76 \mathrm{~m}$ and height of $0.8 \mathrm{~m}$. The sands were mainly of quartz and feldspar grains and subrounded to subangular in shape.

The relationship of Villet and Mitchell is also shown in Figure 9. The differences between Villet and Mitchell's measurements and Schmertmann's (1978) are significant and from as low as $20 \%$ in dense sand with lesser vertical effective stress to $140 \%$ for loose sand subject to more vertical effective stress. This is shown in

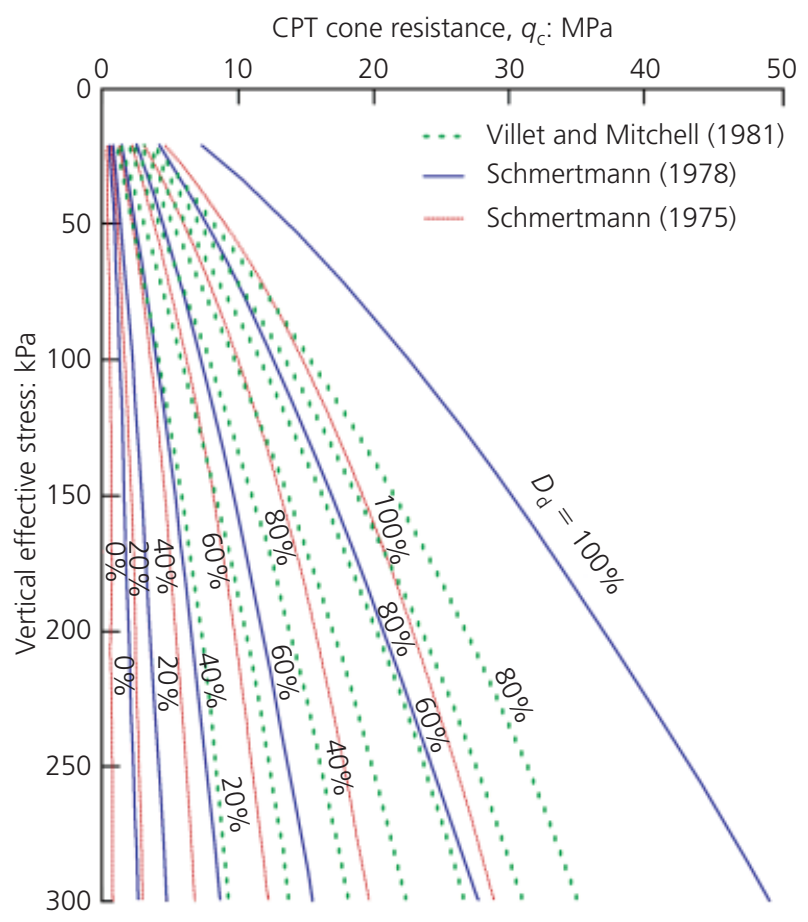

Figure 9. Comparison of relative density $-q_{c}$ relationships by Schmertmann $(1975,1976)$ and Villet and Mitchell (1981)
Table 2. After comparing their calibration chambers and chamber boundary conditions, Villet and Mitchell conclude that these large differences were due to soil type, thus suggesting that cone resistance, vertical stress and relative density relationships are not unique and universal for all sands, but rather a function of the sand being penetrated. This conclusion is applicable to any other research that defines a relationship between these parameters.

In fact, had Villet and Mitchell used the same calibration chamber as Schmertmann, then the differences would have been even larger. A number of researchers such as Parkin (1977) and Parkin and Lunne (1982) have studied the effects of calibration chamber size and boundary conditions. Parkin's results indicate that the ratio of the calibration chamber diameter to the CPT cone diameter and boundary conditions affects the test results whereas either decreasing diameter ratio or maintaining constant stress rather than constant volume boundary conditions results in lower cone resistance.

In addition to the corrections that may be necessary due to the geometry and boundary conditions of the calibration chamber, Bolton and Gui (1993) mention the simulation method of overburden pressure by surcharging as another limitation of the calibration chamber, as the effect of stress gradient due to the self-weight of the soil cannot be simulated in this way. Bolton and Gui conclude that the results obtained from calibration chambers always leave room for questioning, and propose the use of centrifuge testing.

Irrespective of Bolton and Gui's view, calibration chamber testing has remained the dominant approach for developing relative density-CPT correlations. Baldi et al. (1986), who have proposed one of the most popular correlations, performed calibration chamber tests on Ticino sand and Hokksund sand. They proposed an expression in the form of Equation 13

13. $D_{\mathrm{d}}=\frac{1}{C_{2}} \ln \left(\frac{q_{\mathrm{c}}}{C_{\mathrm{o}} \sigma^{\prime C_{1}}}\right)$

where $C_{\mathrm{o}}, C_{1}$ and $C_{2}$ are experimental coefficients.

Vertical effective stress: $\mathrm{kPa}$

$q_{c}$ ratios at relative densities of

\begin{tabular}{lcccc}
\cline { 2 - 5 } & $20 \%$ & $40 \%$ & $60 \%$ & $80 \%$ \\
\hline 100 & 1.7 & 1.9 & 1.5 & $1 \cdot 2$ \\
200 & $2 \cdot 0$ & $2 \cdot 1$ & $1 \cdot 7$ & $1 \cdot 3$ \\
300 & 2.4 & $2 \cdot 2$ & 1.8 & 1.3
\end{tabular}

Table 2. The ratio of $q_{c}$ measured in Villet and Mitchell (1981) to $q_{c}$ predicted by Schmertmann (1978) (after Villet and Mitchell) 
Baldi et al. then refer to earlier work by themselves and define $\sigma^{\prime}$ as the effective vertical stress if the sand is normally consolidated or as the effective horizontal stress or effective mean stress if the soil is overconsolidated. This was based on the fact that using effective vertical stresses in overconsolidated sands led to an overestimation of relative density, as also observed for SPT.

Although Baldi et al. propose experimental coefficients for ten cases of normally consolidated, overconsolidated and normally/ overconsolidated conditions for both Ticino sand and Hokksund sand, for some unknown reason, the normally consolidated Ticino sand has become the better known correlation, as expressed in Equation 14, and what will generally appear in one form or the other when relative density correlations are used as ground improvement acceptance criteria.

14. $D_{\mathrm{d}}=\frac{1}{2 \cdot 41} \ln \left(\frac{q_{\mathrm{c}}}{157 \sigma_{\mathrm{v}}^{\prime 0.55}}\right)$

Had normally consolidated Hokksund sand gained fame, the expression would have had to be as shown in Equation 15. The difference between predicted relative density values using Equations 14 and 15 increases with effective vertical stress and the reciprocal of cone resistance and can be more than $20 \%$. This is yet another example of the fact that relative density correlations are not unique and are dependent on soil type.

$$
D_{\mathrm{d}}=\frac{1}{3 \cdot 29} \ln \left(\frac{q_{\mathrm{c}}}{86 \sigma_{\mathrm{v}}^{\prime 0.53}}\right)
$$

In line with the above, Jamiolkowski et al. (2001) have proposed Equation 16 using Ticino sand, Hukksund sand and Toyoura sand. Here, the data scatter is more for each of the Ticino sand or Hukksund sand equations. Equation 16 yields the lowest estimate of relative density as compared with Equations 14 and 15 in most cases, except for loose sand at high effective vertical stresses.

$$
\text { 16. } D_{\mathrm{d}}=\frac{1}{3 \cdot 10} \ln \left[\frac{\left(q_{\mathrm{c}} / 98 \cdot 1\right)}{17 \cdot 68\left(\sigma_{\mathrm{v}}^{\prime} / 98 \cdot 1\right)^{0.50}}\right]
$$

It should be noted that Jamiolkowski is well aware of the unreliability of relative density as a criterion, and is merely proposing expressions to better the estimate of relative density. Jamiolkowski and Pasqualini (1992) note that quality control that is based only on values of relative density can be insufficient to evaluate the ground modifications achieved by compaction. Even if effective horizontal stresses are used in the estimation expression, they conclude that important factors such as compressibility, ageing and the presence of fines limit the use of correlations as a guide for evaluating in situ density of clean, predominantly silica sands of recent, uncemented deposits. Evaluation of relative density in overconsolidated sands becomes less reliable because of the inherent difficulties in proper assessment of effective horizontal stresses for improved soils.

Relative density correlations are even more unreliable when it comes to calcareous sands. Almeida et al. (1992) carried out calibration chamber tests on the calcareous Quiou sand and concluded that for the same relative density, cone resistance in the calcareous sand was well up to half the value of $q_{\mathrm{c}}$ measured in the silica Ticino sand. The observed trend in the differences was greater for higher relative densities.

More recently, Al-Homoud and Wehr (2006) report that, based on correlation charts of Robertson and Campanella (1985), a relative density of $60 \%$ was required for land reclamation projects (Palm Jumeira) in Dubai. (The authors note that there are no such charts in Robertson and Campanella's cited publication and Al-Homoud and Wehr have probably made a mistake in their reference.) Due to the difficulties in achieving the requested penetration resistance in some zones of the compacted fill, it was felt necessary to verify whether silica sand-based correlation was equally applicable to calcareous sand.

Al-Homoud and Wehr refer to the unpublished work of Gudehus and Cudmani who had performed calibration chamber tests on Dubai's calcareous sand and Karlruhe's quartz sand. According to Al-Homoud and Wehr the calibration chamber diameter and height were respectively $0.95 \mathrm{~m}$ and $1.5 \mathrm{~m}$. The diameter of the CPT rod used in the test was $36 \mathrm{~mm}$. Without entering into a detailed discussion, Al-Homoud and Wehr state that a shell correlation (correction) factor of 1.5 for depths greater than $8 \mathrm{~m}$, 1.6 for depths of 4 to $8 \mathrm{~m}$, and 1.7 for depths less than $4 \mathrm{~m}$ must be applied to Dubai sand. According to this study, these correlation factors should be seen as the lower limit and conservative for calcareous sand if the material in the field is much coarser than the soil fractions used in the experiments since larger shells crush more easily than very small ones. They also note that the penetration resistance for Dubai sand was reported to be about $37 \%$ lower than that of Karlsruhe sand for a medium dense state. They also extend the best-fit exponential curves of Dubai sand to a number of other silica sands to derive a shell correlation factor $f_{\text {shell }}$ which is expressed in Equation 17

$$
\text { 17. } f_{\text {shell }}=0 \cdot 46 D_{\mathrm{d}}+1 \cdot 3629
$$

Comparing Dubai sand with Karlsruhe sand demonstrates that, as previously mentioned, there is no unique relationship between relative density and cone resistance. Similarly, the cone resistance differences between Dubai sand and Karlsruhe sand does not mean that the same differences would be observed between the project criterion's reference sand and Dubai sand. The same is equally true for the expression that was derived in Equation 17. In fact, entering a relative density of 0.6 into Equation 17 will yield a correlation factor of 1.6389 which, if used, would have 
resulted in about $10 \%$ overestimation of the relative density of Dubai sand at depths greater than $8 \mathrm{~m}$.

Furthermore, the calibration chamber diameter to cone diameter ratio in this testing programme was $26 \cdot 4$. This is almost half of the value that Parkin and Lunne (1982) propose for boundary effects to become negligible in normally consolidated dense sands. With the small ratio that has been used by Al-Homoud and Wehr, the difference between the calibration chamber test and the project's acceptance criteria may have simply been due to the boundary effects.

\section{Appropriate acceptance criteria}

Hamidi et al. (2010a, 2010b) report a ground improvement project whose initial acceptance criterion was based on relative density, but calculations were able to demonstrate that it was possible to meet the design criteria with a higher safety factor without complying to the relative density criterion. In Nakilat Ship Repair Yard, a reclamation project that was part of the expansion of Port of Ras Laffan in Qatar, the specifications required relative density to be $60 \%$ based on Baldi et al. (1986) with a correction factor of 1.94 applicable to the CPT cone resistance. Calculation of allowable bearing capacity for the various treated soil profiles showed that even the worst-case profile would still result in a higher bearing capacity than what was calculated for the $60 \%$ relative density design profile. Likewise, calculations showed that for an assumed square footing subject to a load of $4000 \mathrm{kN}$ equivalent to a pressure of $200 \mathrm{kPa}$ the relative density design curve resulted in 40 to $80 \%$ more settlement than any of the treated soil profiles that had not satisfied the relative density specification.

Hamidi et al. (2011) have studied the numerous ways that acceptance criteria can be developed and have concluded that the most appropriate method is to base acceptance criteria on performance directly originating from design criterion without resorting to proxies and go-between parameters such as relative density. The best way to stipulate a design criterion is not by developing a correlation that can be flawed or by developing a performance specification that is based on a minimum test value or test curve, but rather to specify the very design criterion or criteria. Minimum value specifications do not realistically take into account the mass behaviour of the ground, and while any results less than the minimum specified value can immediately lead to failure to reach the specifications, test values above the requirements will literally go unaccounted for. If the requirement is bearing capacity, total or differential settlement, creep, long-term settlement or liquefaction mitigation, the best specification would logically be to specify the design requirement. The minimum test value or test curve is only one right solution and the most unlikely to occur among the thousands of probable acceptable soil profiles that can develop after treatment.

\section{Conclusion}

In this paper, correlations of relative density to field tests have been reviewed and it appears that these correlations do not have the required reliability to be used as ground improvement acceptance criteria. It seems that users of relative density correlations have more confidence in these relationships than the researchers who have themselves developed them.

The relationships between relative density and field tests are not unique and are strongly influenced by sand properties. Parameters such as fines content, grain size, grading, grading curve shape, grain shape, effective vertical or horizontal stresses, mineralogy, compressibility, cementation, overconsolidation, age and crushability all have significant impacts. This has been well observed in research and the wide scatter of data in the studies suggests that proposed correlations may have a notable deviation from even the data points that were used in the studies themselves.

Comparison of studies performed by different researchers demonstrates substantial differences between their estimation methods to the point that if all estimation equations are used, differences could suggest that estimations were no better than wild guesses. Fortunately, there is a much better way to develop a project's acceptance criteria, and that is to base acceptance directly on design criteria. This can be simply achieved by defining the design requirements (such as allowable bearing, settlement limits, liquefaction requirements, etc.) rather than stipulating relative density, or minimum test values.

\section{REFERENCES}

Al-Homoud AS and Wehr W (2006) Experience of vibrocompaction in calcareous sand of UAE. Journal of Geotechnical and Geological Engineering 24(3): 757-774.

Almeida MSS, Jamiolkowski M and Peterson RW (1992) Preliminary result of CPT tests in calcareous Quiou sand. Calibration Chamber Testing: First International Symposium on Calibration Chamber Testing (ISCCT1), Potsdam, NY, 2829 June 1991, 41-53.

ASTM (1969) D 2049-6: Test method for relative density of cohesionless soils. ASTM International, West Conshohocken, PA, USA.

ASTM (2006a) D4253-00 (Reapproved 2006): Standard test methods for maximum index density and unit weight of soils using a vibratory table 15 . ASTM International, West Conshohocken, PA, USA.

ASTM (2006b) D4254-00 (Reapproved 2006): Standard test methods for minimum index density and unit weight of soils and calculation of relative density 9. ASTM International, West Conshohocken, PA, USA.

Baldi G, Bellotti VN, Ghionna N, Jamiolkowski M and Pasqualini E (1986) Interpretation of CPT's and CPTU's - 2nd part: Drained penetration of sands. Proceedings of the 4th International Geotechnical Seminar Field Instrumentation and in-situ Measurements, Nanyang Technological Institute, Singapore, 25-27 November 1986, 143-156. 
Bazaraa AR (1967) Use of Standard Penetration Tests for Estimating Settlements of Shallow Foundations on Sand. $\mathrm{PhD}$ thesis, University of Illinois at Urbana, Urbana, Illinois, USA.

Bolton MD and Gui MW (1993) The Study of Relative Density and Boundary Effects for Cone Penetration Tests in Centrifuge. Technical Report CUED/D-Soils TR 256. Cambridge University, Cambridge, UK.

Bureau of Reclamation (1960) Earth Manual. US Department of the Interior, Denver, CO, USA.

Bureau of Reclamation (1998) Earth Manual, Part 1, 3rd edn. US Department of the Interior, Denver, CO, USA.

Cubrinovski M and Ishihara K (1999) Empirical correlation between SPT N-value and relative density for sandy soils. Soils and Foundations, Japanese Society of Soil Mechanics and Foundation Engineering 39(5): 61-71.

Gibbs KJ and Holtz WG (1957) Research on determining the density of sands by spoon penetration testing. Proceedings of the 4th International Conference on Soil Mechanics and Foundation Engineering, London, 35-39.

Haldar A and Tang WH (1979) Uncertainty analysis of relative density. Journal of Geotechnical Engineering, ASCE 107(7): 899-904.

Hamidi B, Varaksin S and Nikraz H (2010a) Treatment of a hydraulically reclaimed port project by dynamic compaction. Proceedings of the 3rd International Conference on Problematic Soils (PS10), Adelaide, 7-9 April, 113-120.

Hamidi B, Varaksin S and Nikraz H (2010b) Application of dynamic compaction in Port of Ras Laffan expansion project. Proceedings of the 6th Australasian Congress on Applied Mechanics (ACAM6), Perth, Australia, 12-15 December, Paper 1148.

Hamidi B, Nikraz H and Varaksin S (2011) Ground improvement acceptance criteria. Proceedings of the 14th Asian Regional Conference on Soil Mechanics and Geotechnical Engineering, Hong Kong, Paper No 404.

Hamidi B, Varaksin S and Nikraz H (2013) Relative density concept is not a reliable criterion. Proceedings of the Institution of Civil Engineers - Ground Improvement 166(2): $78-85$.

Hatanaka M and Feng L (2006) Estimating relative density of sandy soils. Soils and Foundations, Japanese Society of Soil Mechanics and Foundation Engineering 46(3): 299-313.

Holtz RD (1973) Discussion on determination of relative density of sand below groundwater table. Proceedings of a Conference on Evaluation of Relative Density and its Role in Geotechnical Projects Involving Cohesionless Soils: ASTM STP523-EB.7744-1, Los Angeles, 25-30 June, 376-377.

Holubec I and D'Appolonia E (1973) Effect of particle shape on the engineering properties of granular soils. Proceedings of a Conference on Evaluation of Relative Density and its Role in Geotechnical Projects involving Cohesionless Soils: ASTM STP523-EB.7744-1, Los Angeles, 25-30 June, 304-318.

Jamiolkowski M and Pasqualini E (1992) Compaction of granular soils - remarks on quality control. Proceedings of a Conference on Grouting, Soil Improvement and
Geosynthetics, New Orleans, 25-28 February, 902-914, ASCE Geotechnical Special Publication No. 30. ASCE, Reston, VA, USA.

Jamiolkowski MLO, Presti DCF and Manassero M (2001) Evaluation of relative density and shear strength of sands from CPT and DMT. Soil Behavior and Soft Ground Construction. Geotechnical Special Publication No. 119. ASCE, Boston, USA, pp. 201-238.

Lacroix Y and Horns HM (1973) Direct determination and indirect evaluation of relative density and its use on earthwork construction projects. Proceedings of a Conference on Evaluation of Relative Density and its Role in Geotechnical Projects Involving Cohesionless Soils: ASTM STP523EB.7744-1, Los Angeles, 25-30 June, 251-280.

Liu QB and Lehane BM (2012) The influence of particle shape on the (centrifuge) cone penetration test (CPT). Géotechnique 62(11): 973-984.

Marcuson WF III (1978) Determination of in situ density of sands. Proceedings of a Conference on Dynamic Geotechnical Testing, ASTM STP 654, Denver, 28 June, 318-340.

Marcuson WF III and Bieganousky WA (1977) Laboratory standard penetration tests on fine sands. Journal of Geotechnical Engineering, ASCE 103(6): 565-589.

Mayne PW and Kulhawy FH (1982) $\mathrm{K}_{0}$-OCR relationship in soil. Journal of Geotechnical Engineering, ASCE 108(6): 851872.

Meyerhof GG (1957) Discussion on research on determining the density of sands by spoon penetration testing. Proceedings of the 4th International Conference on Soil Mechanics and Foundation Engineering, London, 110.

Mitchell JK and Gardner WS (1975) State of the art: in situ measurement of volume change characteristics. Proceedings of ASCE Conference on in situ Measurements of Soil Properties, Raleigh, North Carolina, pp. 279-345.

Moretto O (1954) Subsoil investigation for a bridge over the Parana river, Argentina. Géotechnique 4(4): 137-142.

Osterberg JO and Varaksin S (1973) Determination of relative density of sand below groundwater table. Proceedings of a Conference on Evaluation of Relative Density and its Role in Geotechnical Projects Involving Cohesionless Soils: ASTM STP523-EB.7744-1, Los Angeles, 25-30 June, 364-378.

Parkin AK (1977) The Friction Cone Penetrometer: Laboratory Calibration for the Prediction of Sand Properties. Norwegian Geotechnical Institute, Oslo, Norway, Internal Report No. 52108-5.

Parkin AK and Lunne T (1982) Boundary effects in the laboratory calibration of a cone penetrometer for sand. Proceedings of the 2nd European Symposium on Penetration Testing, Amsterdam, 761-767.

Peck RB and Bazaraa AR (1969) Discussion of settlement of spread footings on sand. Journal of Soil Mechanics and Foundations Division, ASCE 95(3): 905-909.

Robertson PK and Campanella R (1985) Liquefaction potential of sands using the CPT. Journal of Geotechnical Engineering, ASCE 111(3): 384-403. 
Schmertmann JH (1975) State of the art paper: measure of in situ strength. Proceedings of ASCE Conference on in situ Measurements of Soil Properties, Raleigh, North Carolina, pp. $57-138$.

Schmertmann JH (1976) An Updated Correlation between Relative Density and Fugro-type Electric Cone Bearing $q_{\mathrm{c}}$. Waterways Experiment Station, Vicksburg, MS, USA, Vol. 145, Contract report, DACW 38-76-M 6646.

Schmertmann JH (1978) Guidelines for Cone Penetration Test, Performance and Design. Federal Highway Administration, Washington, DC, USA, Vol. 145, Report FHWA-TS-78-209.

Skempton AW (1986) Standard penetration test procedure and the effects in sands of overburden pressure, relative density, particle size, ageing and overconsolidation. Géotechnique 36(3): 425-447.

Tatsuoka F, Tokida K, Yasuda S et al. (1978) A method for estimating undrained cyclic strength of sandy soils using standard penetration resistance. Soils and Foundations, Japanese Society of Soil Mechanics and Foundation Engineering 18(3): 43-58.

Terzaghi K and Peck RB (1948) Soil Mechanics in Engineering Practice. Wiley, New York, USA.

Tokimatsu K and Yoshimi Y (1983) Empirical correlation of soil liquefaction based on SPT-N value and fines content. Soils and Foundations, Japanese Society of Soil Mechanics and Foundation Engineering 23(4): 56-74.

Varaksin S (1970) Determination of Sand Density Below Groundwater Table. MSc thesis, Northwestern University at Evanston, IL, USA.

Villet WCB and Mitchell JK (1981) Cone resistance, relative density and friction angle. Proceedings of a Symposium on Cone Penetration Testing and Experience, ASCE National Convention, St Louis, October, pp. 178-208.

Wu TH (1957) Relative density and shear strength of sands. Journal of the Soil Mechanics and Foundations Division, ASCE 83(1): 1161-1123.

Yoshimi Y and Tohno I (1973) Statistical significance of the relative density. Proceedings of a Conference on Evaluation of Relative Density and its Role in Geotechnical Projects involving Cohesionless Soils: ASTM STP523-EB.7744-1, Los Angeles, 25-30 June, 74-84.

Youd TL (1973) Factors controlling maximum and minimum densities of sands. Proceedings of a Conference on Evaluation of Relative Density and its Role in Geotechnical Projects involving Cohesionless Soils: ASTM STP523EB.7744-1, Los Angeles, 25-30 June, 98-112.

\section{WHAT DO YOU THINK?}

To discuss this paper, please email up to 500 words to the editor at journals@ice.org.uk. Your contribution will be forwarded to the author(s) for a reply and, if considered appropriate by the editorial panel, will be published as a discussion in a future issue of the journal.

Proceedings journals rely entirely on contributions sent in by civil engineering professionals, academics and students. Papers should be 2000-5000 words long (briefing papers should be 1000-2000 words long), with adequate illustrations and references. You can submit your paper online via www.icevirtuallibrary.com/content/journals, where you will also find detailed author guidelines. 